\section{Estudo e avaliação dos dados de apreensões de produtos de origem animal pelo Serviço de Vigilância Agropecuária no Rio de Janeiro, em voos internacionais e sua interação com possíveis riscos sanitários}

\author{
Study and evaluation of animal products of seizures data for \\ Agricultural Monitoring Service in Rio de Janeiro in international \\ flights and it is interaction with possible health risk
}

\begin{abstract}
Carlos Alberto Magioli*, Sérgio Borges Mano ${ }^{2}$, Jorge de Rezende ${ }^{3}$, Clayton Bernardelli Gitti ${ }^{4}$ \& Eliane Teixeira Mársico²

'Médico veterinário, DSc. Programa de Pós-graduação em Higiene Veterinária e Processamento Tecnológico de Produtos de Origem Animal, Faculdade de Veterinária - FV, Universidade Federal Fluminense - UFF, Niterói, RJ, Brasil

2Médicos veterinários, DScs. Departamento de Tecnologia dos Alimentos, Faculdade de Veterinária - FV, Universidade Federal Fluminense - UFF, Niterói, RJ, Brasil

${ }^{3}$ Professor, Doutor em Computação de Alto Desempenho. Instituto Alberto Luiz Coimbra de Pós-graduação e Pesquisa em Engenharia - COPPE, Universidade Federal do Rio de Janeiro - UFRJ, Rio de Janeiro, RJ, Brasil

${ }^{4}$ Médico veterinário, DSc. Departamento de Epidemiologia e Saúde Pública, Universidade Federal Rural do Rio de Janeiro UFRRJ, Seropédica, RJ, Brasil
\end{abstract}

\section{Resumo}

O objetivo do presente trabalho foi estudar e avaliar a incidência de apreensões de produtos de origem animal pelo Serviço de Vigilância Agropecuária no Aeroporto internacional do Rio de Janeiro no período de 2010 a 2014, associando-as as possibilidades de veiculação de enfermidades animais, principalmente exóticas. A metodologia empregada consistiu de uma análise de dados gerados a partir dos registros do Serviço de Vigilância Agropecuária junto ao aeroporto internacional do Rio de Janeiro, de apreensões de produtos de origem animal em bagagens de passageiros oriundos de voos internacionais no período de 2010 a 2014. Os dados utilizados foram classificados como categóricos, por expressarem suas características de forma qualitativa e as variáveis estudadas, se referem à procedência, produtos e classificação macro desses produtos, não tendo nenhuma ordem de prioridades e nem de importância caracterizando assim, esses dados como categóricos nominais. Neste estudo o produto na classificação carne foi o que apresentou maior índice de apreensão com um total de 11.229,883 kg, seguido do classificado como laticínio com 9.505,175 kg, pescado com 7.625,893, mel de abelha com 827,528 kg e ovo com 50,967 kg, sendo que individualmente o produto queijo foi o mais apreendido com $7.932,495 \mathrm{~kg}$ seguido de pescado com 3.594,367 kg e presunto com 1.948,594 kg. O país que teve o maior volume de produtos apreendidos foi Portugal com 12.668,795 kg, seguido de Itália com 2.530,456 kg, China com 2.365,968 kg e Espanha com 2.209,621 kg, concluindo-se que os produtos apreendidos poderão ter potencial risco de introdução de patologias para os animais.

Palavras-chave: vigilância agropecuária, fiscalização, barreiras zoo-sanitárias.

\footnotetext{
Abstract

The objective of this work was to study and evaluate the incidence of seizures of animal products by the Agricultural Security Service in the international Rio de Janeiro Airport in 2010 to 2014, associating them with the possibilities of transmitting the animal diseases, especially exotic. The methodology resulted from an analysis of data from the records of the Agricultural Security Service by the international airport of Rio de Janeiro, seizures of animal products in passenger luggage from international flights in the period 2010 to 2014. Data used were classified as categorical, for expressing their characteristics qualitatively and variables refer to the origin, product and classification macro those products, having no order of priority and not of importance featuring so these data as nominal categorical. In this study the product in meat classification showed the highest seizure rate a total of $11,229.883 \mathrm{~kg}$, followed by classified as dairy with $9505.175 \mathrm{~kg}$, with fish 7625.893 , honey with $827.528 \mathrm{~kg}$ and egg with $50.967 \mathrm{~kg}$, with individual product
}

Como citar: Magioli, C. A., Mano, S. B., Rezende, J., Gitti, C. B., \& Mársico E. T. (2017). Estudo eavaliação dos dados de apreensões de produtos de origem animal pelo Serviço de Vigilância Agropecuária no Rio de Janeiro, em voos internacionais e sua interação com possíveis riscos sanitários. Brazilian Journal of Veterinary Medicine, 39(2), 90-99. doi: 10.29374/2527-2179.bjvm031517

Fonte de financiamento: Nenhuma.

Conflito de interesses: Os autores declaram não haver conflito de interesses que precisam ser informados.

Recebido: Junho 06, 2016

Aceito: Janeiro 22, 2017.

O estudo foi realizado no Serviço de Vigilância Agropecuária (SVA/AIRJ) da Superintendência Federal de Agricultura do Rio de Janeiro, Rio de Janeiro, RJ, e na Faculdade de Veterinária da Universidade Federal Fluminense, Niterói, RJ, Brasil.

\section{*Correspondência \\ Carlos Alberto Magioli \\ Programa de Pós-graduação em Higiene Veterinária e Processamento Tecnológico de Produtos de Origem Animal, Faculdade de Veterinária - FV, Universidade Federal Fluminense - UFF \\ Rua Vital Brasil Filho, 64, Santa Rosa CEP 24230-340 - Niterói (RJ), Brasil E-mail: camagioli@yahoo.com.br}

Copyright Magioli et al. Este é um artigo publicado em acesso aberto (Open Access) sob a licença Creative Commons Attribution Non-Commercial, que permite uso, distribuição e reprodução em qualque meio, sem restrições desde que sem fins comerciais e que o trabalho original seja corretamente citado. 
cheese was the most seized with $7932.495 \mathrm{~kg}$ followed by fish with $3594.367 \mathrm{~kg}$ and ham with $1948.594 \mathrm{~kg}$. The Country that had the largest volume of seized goods was Portugal with $12,668.795 \mathrm{~kg}$, followed by Italy with 2,530.456 kg, China with 2,365.968 kg and Spain with 2,209.621 kg, concluding that the seized products may have potential input conditions for the animals.

Keywords: agricultural monitoring, inspection, zoo-sanitary barriers.

\section{Introdução}

O Brasil éum grande produtor mundial de proteína animal e tem no mercado interno o principal destino de sua produção (Brasil, 2015a).

Entretanto a cada ano, a participação brasileira no comércio internacional vem crescendo, com destaque para a produção de carne bovina, suína e de frango. A expectativa é que até 2020 a produção nacional de carnes suprirá $44,5 \%$ do mercado mundial, com estimativas indicando que o Brasil pode manter posição de primeiro exportador mundial de carnes bovina e de frango (Brasil, 2015b).

O Brasil ocupa importante posição no cenário da avicultura mundial, pois é o maior exportador de carne de frango e éum país livre da influenza aviária, visto que nenhum foco da doença foi ainda, registrado no país. Porém, caso a doença chegue, os danos podem ser desastrosos. Se a doença chegar ao Brasil, será uma tragédia para milhares de produtores integrados ou independentes e frigoríficos, portanto, um drástico efeito dominó em toda a cadeia. Consequentemente, seria drástico o impacto também na balança comercial brasileira, considerando que o complexo carne ocupa importante lugar e a carne de frango disputa a primeira posição em exportação e receita neste complexo (Tavares \& Ribeiro, 2007).

Deacordo com Corbellini (2007) o agronegócio no Brasilé de extrema importância para economia, justificando-se o emprego de métodos cada vez mais avançados para o controle, monitoramento e determinação do status sanitário animal, com intuito de aumentar a credibilidade do produto brasileiro no mercado internacional.

Com a globalização da economia, redução das barreiras tarifárias e aumento das trocas comerciais entre os países, há um incremento do risco do intercâmbio internacional de agentes etiológicos de enfermidades transmitidas por alimentos, tornando-se de grande importância os controles destes produtos, a começar pela fiscalização pelo serviço veterinário oficial nas fronteiras internacionais, considerada uma excelente estratégia de defesa contra o ingresso de enfermidades (U. S. Department of Agriculture, 2003).

Um exemplo marcante deste fato foi à entrada da peste suína africana no Brasil, que se deveu a restos de alimentos de aviões de companhias aéreas de Portugal e da Espanha, retirados no aeroporto internacional do Rio de Janeiro e levados para uma criação de suínos, situada no município de Paracambi, RJ (Tokarnia et al., 2004).

A ocorrência de surtos de enfermidades contagiosas animais pode representar sérias consequências econômicas, cujos prejuízos podem resultar tanto em proibições internacionais às exportações de animais e produtos do país acometido, quanto no próprio mercado interno, devido às restrições ao trânsito de animais e produtos, cujas implicações comerciais determinam o enfraquecimento do comércio local, aumento do desemprego e consequente escassez de renda (Horst et al., 1998).

Para Moura (2004) o incremento do risco mundial de difusão de agentes patológicos motivado pela globalização e o consequente incremento do comércio internacional conduziram, nos últimos anos, a verdadeiras catástrofes como as crises da encefalopatia espongiforme bovina (BSE), da febre aftosa e recentemente da gripe aviária altamente patológica. Outras enfermidades animais, endêmicas nos países em via de desenvolvimento ou em transição, limitam a produção de alimentos e os intercâmbios comerciais desses países. A intensificação do comércio internacional implica maior risco potencial para a introdução de enfermidades; por isso, é essencial que se estabeleçam mecanismos que, ao mesmo tempo em que permitam as transações comerciais, protejam a situação sanitária dos países envolvidos.

As barreiras sanitárias impostas pelos países importadores, em substituição às barreiras tarifarias, constituem o maior obstáculo para acesso aos mercados internacionais. Diferente do que antes acontecia, na atualidade todos os países se protegem com rigorosas exigências sanitárias antes de abrir seus mercados (Soncini, 2004). 
Uma das missões da OIE é garantir a transparência do estatus de saúde animal no mundo. Entre as obrigações formais dos países membros inclui o envio de informações da maneira mais oportuna e transparente sobre as doenças relevantes dos animais, incluindo zoonoses presentes em seus territórios. Para este efeito foi instituída uma lista de doenças de declaração obrigatória à OIE para animais terrestres e aquáticos que compõe o Sistema de Informação Mundial de Saúde Animal (Organização Internacional de Saúde, 2013).

Assim, tomando como base a lista de enfermidades, infecções e infestações da Organização Internacional de Saúde (2016) doenças dos animais não descritas no Brasil como a Brucelose (Brucella melitensis), Febre hemorrágica de Crimea-Congo, Infecção pelo vírus da febre do Valle do Rift, Peste suína africana, Encefalopatía espongiforme bovina, Infecção pelo vírus de influenza aviaria, Infecção das abelhas melíferas por Melissococcus plutonius (Loque européia), Infestacção por Aethina tumida (besouro das colmeias), Necrose hematopoiética epizoótica, Necrose hematopoiética infecciosa e Septicemia hemorrágica viral, podem ser introduzidas no país através de diversos produtos de origem animal.

De acordo com o Relatório do Tribunal de Contas da União (Brasil, 2006b), informações da Embrapa citam que, com relação ao ingresso ilegal de produtos no país os principais pontos de entrada são por bagagem de passageiros de viagens internacionais e por encomenda postal.

Em2003, o diagnóstico da Encefalopatia Espongiforme Bovina (BSE ou “Doença da Vaca Louca”) em bovinos, nos EUA, resultou no fechamento imediato de quase $90 \%$ do mercado importador da carne americana. Mesmo que a perda de acesso ao mercado internacional possa ser breve, as doenças animais geram custos consideráveis com controle da enfermidade, pagamento de indenizações e perdas relacionadas com produção e industrial (Rich et al., 2007).

Para Weiblen (2013) é de conhecimento geral a importância das barreiras sanitárias, pois a introdução de um agente pode inviabilizar parcial ou totalmente uma cadeia produtiva.

Os alimentos de origem animal trazidos ilegalmente de países terceiros para a Comunidade Europeia representam um risco para a introdução de doenças. Isso pode levar a surtos de doenças animais com custos económicos e sociais significativos e restrições comerciais subsequentes graves. Bagagem de passageiro é a rota mais provável pela qual os produtos ilegais entram na Alemanha através do Aeroporto Internacional de Frankfurt e Berlim. A maioria dos alimentos contaminados foram carne (33\%) ou produtos à base de carne (42\%), e produtos de leite (21\%), considerando-se que apenas uma pequena fração dos passageiros que chegam é submetida a controles personalizados. (Beutlich et al., 2015)

Na Austrália, que tem um dos mais efetivos serviços de quarentena em todo o mundo, cerca de 9 em cada 10 passageiros que chegam têm suas bagagens inspecionadas pelo Australian Quarantine and Inspection Service (AQIS); usando uma combinação de cães farejadores, exame de Raios-X e inspeção física das bagagens (Department of Agriculture Fisheries and Foresty, 2013).

Conforme constam nos Relatórios Estatísticos de Fiscalização de Cargas e Bagagens do Serviço de Vigilância Agropecuária no Aeroporto Internacional do Rio de Janeiro - SVA/AIRJ, no período de 2010 a 2012 foram fiscalizados pelo Serviço, 6012 voos internacionais que chegaram a este aeroporto. (Brasil, 2015c)

A Vigilância Agropecuária Internacional (VIGIAGRO), criada com a publicação da Portaria SDA no 297, de 22 de junho de 1998, é a área do Ministério da Agricultura, Pecuária e Abastecimento, que atua na fiscalização da importação e exportação, bem como no trânsito internacional de animais, seus produtos, subprodutos, materiais de multiplicação animal, materiais de pesquisa e insumos, tendo unidades estrategicamente distribuídas em portos marítimos efluviais, aeroportos internacionais, postos de fronteira e aduanas especiais (Brasil, 1998).

O Decreto nO 5.741, de 30 de março de 2006, delegou ao Ministério da Agricultura, Pecuária e Abastecimento, o estabelecimento dos corredores de importação e exportação de animais, vegetais, insumos, inclusive alimentos para animais e produtos de origem animal e vegetal, com base em análises de risco, requisitos e controles sanitários, "status" zoo-sanitário e fitossanitário, localização geográfica e disponibilidade de infraestrutura e de recursos humanos (Brasil, 2006a).

Esta atividade está representada no aeroporto internacional do Rio de Janeiro - Galeão - Antônio Carlos Jobim, pelo Serviço de Vigilância Agropecuária-SVA/AIRJ, ao qual cabe a fiscalização de animais, vegetais e seus produtos derivados, destinados ao Estado do Rio de Janeiro ou em 
trânsito, contando com um efetivo de fiscais federais agropecuários em revezamento diuturno, abrangendo os terminais de passageiros e de cargas.

O objetivo do presente trabalho foi estudar e avaliar no período de 2010 a 2014, através da compilação dos dados registrados nos termos de apreensões de bagagens e encomendas, a incidência de apreensões de produtos de origem animal pelo Serviço de Vigilância Agropecuária no Aeroporto internacional do Rio de Janeiro - Galeão - Antônio Carlos Jobim, identificando os de maior incidência, o país de origem do maior quantitativo de produtos apreendidos, associando o risco potencial de introdução através deles, de enfermidades animais, principalmente exóticas.

\section{Material e métodos}

O presente estudo, segundo a sua finalidade, inclui-se na classificação de pesquisa aplicada constituindo-se em um estudo elaborado com o objetivo de resolver problemas específicos no âmbito da sociedade. Em uma primeira etapa foi realizada a compilação dos dados registrados no documento "termo de apreensão de bagagem e encomenda" emitido pelo Serviço de Vigilância Agropecuária, quando da apreensão de produtos de origem animal transportados irregularmente em bagagens de passageiros oriundos de voos internacionais. Em seguida estes dados foram organizados em planilhas microsoft excel, com dados relacionados a data da apreensão, nome da companhia aérea transportadora, número do voo, procedência, tipo de produto apreendido, quantidade e classificação de acordo com a matéria prima em carne, laticínio, pescado, mel de abelha e ovo. Através de revisão bibliográfica foram listadas a principais doenças dos animais de ocorrência mundial, passiveis de serem transmitidas pelos diversos alimentos de origem animal, como forma de demonstrar o potencial risco zoo-sanitário que estes produtos poderiam representar.

A pesquisa foi desenvolvida na forma descritiva por utilizar técnica padrão de coleta de dados a partir dos registros do Serviço de Vigilância Agropecuária junto ao aeroporto internacional do Rio de Janeiro, de apreensões de produtos de origem animal em bagagens de passageiros oriundos de voos internacionais.

As bagagens dos passageiros dos voos selecionados para fiscalização, após serem desembarcadas das aeronaves, eram passadas pelo Equipamento de Inspeção por Raios X, separando às que apresentavam características de conterem produtos de origem animal ou vegetal. Em seguida eram levadas para bancada de fiscalização do Serviço de Vigilância Agropecuária na área alfandegada do terminal de desembarque, para serem abertas pelos passageiros proprietários e devidamente fiscalizadas. Caso contivessem produtos com ingresso impedido no país, estes eram apreendidos, desnaturados e colocados nas embalagens de polietileno próprias e identificadas, emitindo-se em seguida o competente documento de apreensão, termo de fiscalização de bagagem/encomenda, com a identificação do passageiro, da origem e dos produtos apreendidos, tipo e quantidade. Outra metodologia adotada era a fiscalização das bagagens em conjunto com a receita federal, no momento em que o passageiro deixava a zona primária do aeroporto, sendo que neste caso, a inspeção era feita por amostragem e os procedimentos no caso de bagagens suspeitas seguiam os anteriormente descritos.

Conforme observação do autor, não havia um critério institucional para a definição dos voos a serem fiscalizados a cada momento ficando esta escolha a cargo da equipe em serviço ou da aquiescência do órgão da Receita Federal do Brasil havendo um esforço de trabalho mais voltado para os voos originários principalmente da República Portuguesa e ainda com menor intensidade da República da Itália, países da África, Ásia e Oriente médio.

Esta preferência se justifica por ter a República Portuguesa tradição na elaboração de produtos de origem animal artesanais, pelo número de seus cidadãos e de descendentes residentes no Brasil, acrescido do fato do último grande episódio de transmissão de doença exótica, peste suína africana, ter sido desencadeado a partir de material desta procedência.

\section{Resultados}

No período estudado foi estimado que 74.510 voos internacionais que chegaram ao Aeroporto Internacional do Rio de Janeiro Antônio Carlos Jobim, transportando 9.652.261 passageiros, com uma média de 41,394 voos diários com 129,54 passageiros por aeronave. 
Ao considerar-se apenas o período de 2010 a 2012 houve a movimentação de 45.051 voos que cotejados com os dados de Brasil (2015c) de 6.012 fiscalizados concluiu-se que em média 14,34\% dos voos foram submetidos à fiscalização e consequentemente 85,66\% não o foram.

Em relação aos produtos apreendidos, levando em consideração a classificação adotada nesta pesquisa, observou-se 86 tipos de produtos de origem animal diferentes, sendo que 48 corresponderam a classificação carne, 21 a classificação pescado, 12 a classificação laticínio, 3 a classificação mel de abelha e 2 a classificação ovo.

As apreensões totalizaram 29.239,446 kg (Figura 1), equivalendo a uma média 5.847,89 kg por ano, 487,32 kg por mês e 16,24 kg por dia.

Considerando-se a classificação dos produtos adotada para a avaliação, pode-se observar na Figura 1 que em todos os anos estudados a carne foi o que apresentou maior quantidade (kg) de produtos apreendidos, seguido de laticínio, pescado, mel de abelha e ovo, exceto para o ano de 2013 em foi apreendida uma maior quantidade de produto pescado do que de laticínio.

A variação do quantitativo de apreensões depende diretamente do número de voos fiscalizados que deveria ser definido por protocolo de atuação do Serviço de Vigilância Agropecuária. Como, conforme observação do autor, não existiu deliberação para esta meta os valores ficaram sujeitos ao critério da equipe de fiscalização com respeito ao quantitativo de voos a serem fiscalizados ou a aquiescência da Receita Federal do Brasil.

Assim ao concluir-se que 14,34\% dos voos sofreram fiscalização é estimado que entrou ilegalmente no Brasil no período estudado um total de $174.661,817 \mathrm{~kg}$ de produtos de origem animal diversos, que em função de suas origens ou de suas matérias primas podem ser considerados de risco zoosanitário.

Com relação a origem dos produtos apreendidos do total de 93 países, 32 estão localizados no continente europeu, 20 no continente americano, 22 no continente asiático, 18 no continente africano e 1 na Oceania.

Na Figura 2 pode-se observar que do total de $25.974,332 \mathrm{~kg}$ referente ao quantitativo dos 10 países com maior incidência de apreensões de produtos de origem animal, 19.608,788 kg são originários de países do continente europeu, o que representa 75,49\% deste total ou 67,06\% do total geral no período estudado que foi de 29.239,446 kg.

Considerando os 10 países os maiores volumes de apreensões, Portugal lidera com $12.668,775 \mathrm{~kg}$ correspondendo a 48,77\% do total deles ou 43,32\% do total geral. Tendo ainda Portugal como referencia, as apreensões originárias da Itália, segundo pais no quantitativo geral dos produtos apreendidos com 2530,456 kg, correspondem a 19,97\% do primeiro, representando um volume cinco vezes menor.

Conforme observação do autor, por não haver um critério institucional para a definição dos voos a serem fiscalizados o esforço de trabalho da equipe do SVA/AIRJ está mais voltado para os

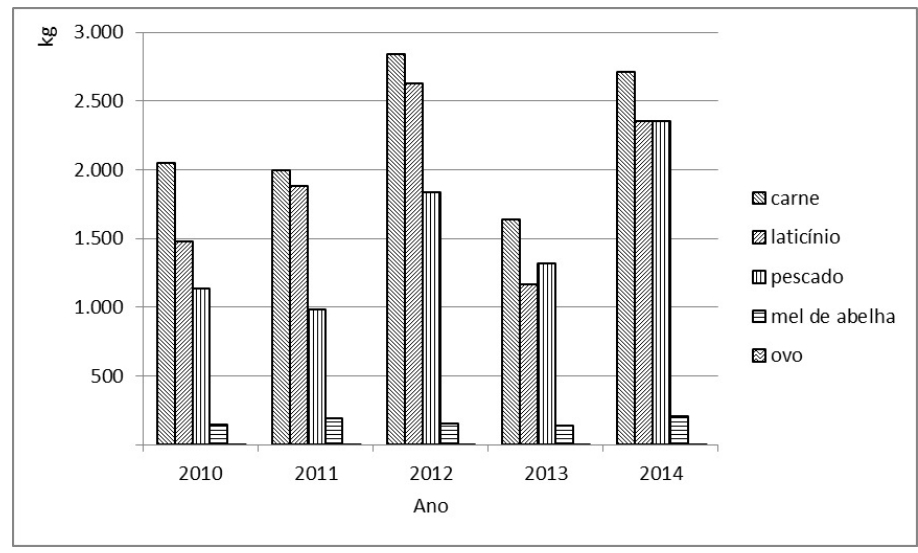

Figura 1. Quantidade (kg) de produtos apreendidos pelo Serviço de Vigilância Agropecuária no Aeroporto Internacional do Rio de Janeiro de acordo com a sua classificação nos anos de 2010 a 2014. 
voos originários de Portugal em função da tradição deste país na elaboração de produtos de origem animal artesanais, pelo número de seus cidadãos e descendentes residentes no Brasil, acrescido do fato do ultimo grande episódio de transmissão de doença exótica, peste suína africana, ter sido desencadeado a partir de material desta procedência, o que justifica esse volume de apreensões quando comparado com os demais países.

Assim os produtos de origem animal trazidos em bagagens de passageiros originários de Portugal, pela grande quantidade dos artesanais sem nenhum controle higiênico, tecnológico e sanitário, representam alto risco de albergarem agentes capazes de representar risco zoo-sanitário para o Brasil.

Os quantitativos das apreensões por procedência no período estudado estão representados na Tabela 1.

Os valores demonstrados na Tabela 1 ratificam a conclusão da Figura 2 por ter sido Portugal em todos os anos estudados o país de procedência da maioria dos produtos de origem animal apreendidos. Entretanto, independente do quantitativo geral (Figura 2) remeter a Itália como o segundo país com maior índice de apreensões, ao considerar-se a avaliação anual, não houve regularidade com respeito a este resultado.

No total geral dos anos estudados, os dez produtos mais apreendidos estão relacionados na Figura3.

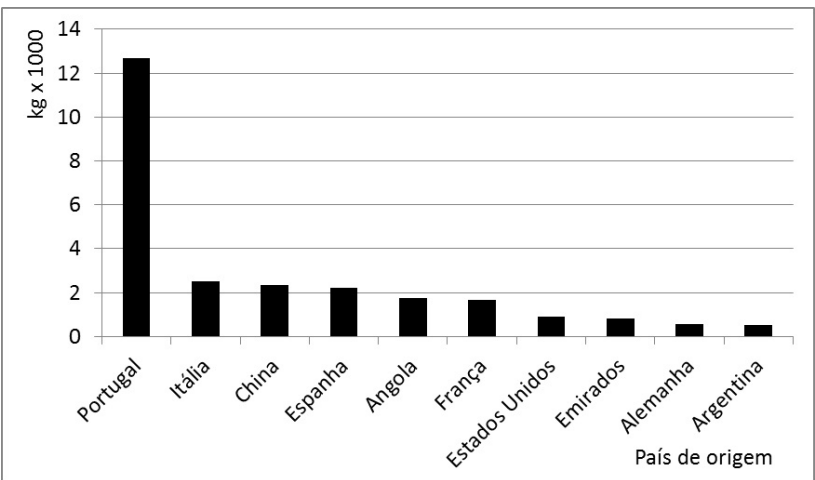

Figura 2. Dez Países com maiores quantitativos (kg x 1000) de apreensões de produtos de origem animal pelo Serviço de Vigilância Agropecuária no Aeroporto Internacional do Rio de Janeiro no período de 2010 a 2014.

Tabela 1. Quantidade total (kg) de produtos de origem animal apreendidos pelo Serviço de Vigilância Agropecuária no Aeroporto Internacional do Rio de Janeiro, por procedência no período de 2010 a 2014.

\begin{tabular}{|c|c|c|c|c|c|c|c|c|c|}
\hline \multicolumn{2}{|c|}{2010} & \multicolumn{2}{|c|}{2011} & \multicolumn{2}{|c|}{2012} & \multicolumn{2}{|c|}{2013} & \multicolumn{2}{|c|}{2014} \\
\hline País & Total & País & Total & País & Total & País & Total & País & Total \\
\hline Portugal & 2268,690 & Portugal & 2765,605 & Portugal & 3261,610 & Portugal & 1530,485 & Portugal & 2842,405 \\
\hline Espanha & 709,955 & Itália & 469,350 & Itália & 783,119 & China & 718,357 & Angola & 729,257 \\
\hline França & 488,306 & Espanha & 332,466 & Espanha & 712,203 & Angola & 445,623 & Emirados & 657,484 \\
\hline Itália & 453,328 & França & 273,164 & China & 563,863 & Espanha & 212,973 & Itália & 615,506 \\
\hline China & 230,336 & China & 260,283 & França & 452,751 & Itália & 209,153 & China & 593,129 \\
\hline Alemanha & 120,059 & Angola & 185,543 & Angola & 303,215 & EUA & 206,651 & EUA & 413,249 \\
\hline Angola & 82,288 & Alemanha & 150,396 & Alemanha & 167,328 & Emirados & 164,987 & França & 320,433 \\
\hline EUA & 56,992 & EUA & 113,895 & Argentina & 128,676 & França & 116,346 & Espanha & 242,034 \\
\hline Suíça & 49,605 & Argentina & 103,719 & EUA & 126,699 & Honduras & 87,500 & Argentina & 208,424 \\
\hline Holanda & 47,659 & Suíça & 58,469 & Inglaterra & 107,571 & Argentina & 72,874 & Alemanha & 111,133 \\
\hline
\end{tabular}


De acordo com a Figura 3, pode-se observar que, ao ser considerado o total geral de cada produto no período estudado, o queijo foi o mais apreendido representando quantidade superior ao dobro da quantidade do segundo produto mais apreendido, pescado. Entretanto, cotejando-se com os resultados expressos na Figura 1, observa-se que ao se avaliar os produtos com respeito às classificações adotadas, aqueles classificados como carne foram os de maiores quantitativos totais. Este resultado encontra justificativa no fato dos produtos classificados como carne terem uma maior diversidade, 48 no total, do que os classificados como laticínio, 12 no total.

Considerando-se apenas o produto carne, a quantidade apreendida no período estudado foi de 80,472 kg em 2010, 107,350 kg em 2011, 323,647 kg em 2012, 418,811 kg em 2013 e 420,136 kg em 2014. Como esses valores correspondem a 14,34\% dos voos a estimativa é que pelos demais 85,66\% voos não fiscalizados entraram ilegalmente no país 480,699 kg em 2010, 641,255 kg em 2011, 1.933,305 kg em 2012, 2.501,767 kg em 2013 e 2.509,682 kg em 2014.

No período de 2010 a 2014, as apreensões referentes aos 10 principais produtos, encontram-se na Tabela 2.

Dentre os produtos identificados como carne estão incluídas as carnes bovinas nos diversos tipos de apresentação e outros produtos cárneos identificados desta forma no termo de fiscalização de bagagem/encomenda emitido pelo fiscal federal agropecuário que procedeu a apreensão.

Incluídos nos produtos denominados embutidos estão os não identificados no momento da fiscalização, porém com características tecnológicas inerentes a este tipo de produto e assinalados desta forma no mesmo documento de fiscalização.

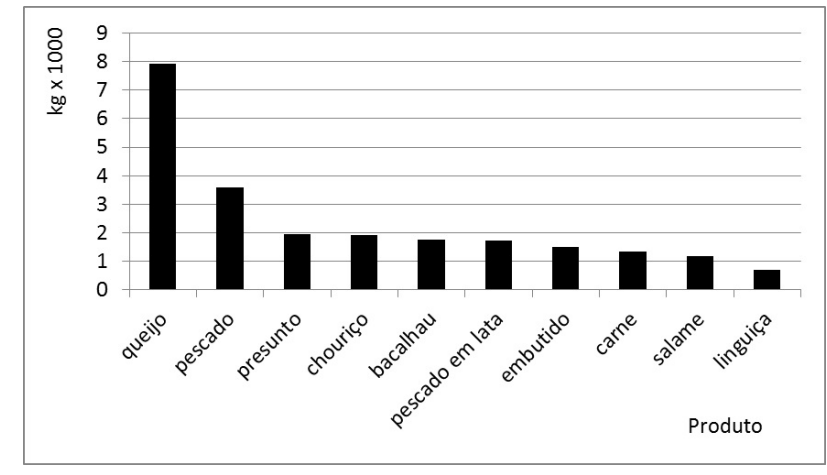

Figura 3. Produtos de origem animal com maiores quantidades de apreensões pelo Serviço de Vigilância Agropecuária no Aeroporto Internacional do Rio de Janeiro no período de 2010 a 2014.

Tabela 2. Quantidades dos dez produtos de origem animal mais apreendidos pelo Serviço de Vigilância Agropecuária no Aeroporto Internacional do Rio de Janeiro no período de 2010 a 2014

\begin{tabular}{|c|c|c|c|c|c|c|c|c|c|}
\hline \multicolumn{2}{|c|}{2010} & \multicolumn{2}{|c|}{2011} & \multicolumn{2}{|c|}{2012} & \multicolumn{2}{|c|}{2013} & \multicolumn{2}{|c|}{2014} \\
\hline Produto & $\mathrm{kg}$ & Produto & $\mathrm{kg}$ & Produto & kg & Produto & $\mathrm{kg}$ & Produto & $\mathrm{Kg}$ \\
\hline queijo & 1415,854 & Queijo & 1694,318 & queijo & 2373,279 & queijo & 889,532 & queijo & 1559,512 \\
\hline presunto & 464,024 & chouriço & 445,216 & pescado & 821,902 & pescado & 868,494 & pescado & 1283,272 \\
\hline pesc lata & 458,254 & presunto & 427,258 & bacalhau & 557,661 & carne & 418,811 & pesc lata & 521,868 \\
\hline chouriço & 411,543 & bacalhau & 341,300 & presunto & 533,907 & chouriço & 273,067 & embutido & 493,974 \\
\hline salame & 365,058 & pescado & 322,655 & chouriço & 417,470 & embutido & 269,350 & carne & 420,136 \\
\hline bacalhau & 335,758 & embutido & 257,801 & salame & 347,369 & presunto & 212,821 & laticínio & 399,796 \\
\hline pescado & 298,044 & pesc lata & 249,095 & embutido & 338,579 & bacalhau & 186,594 & chouriço & 364,586 \\
\hline embutido & 150,003 & mel & 192,175 & carne & 323,647 & pesc lata & 168,603 & bacalhau & 346,119 \\
\hline mel & 144,523 & salame & 169,902 & pesc lata & 323,182 & mel & 135,496 & presunto & 310,584 \\
\hline linguiça & 142,469 & linguiça & 153,408 & linguiça & 284,269 & laticínio & 122,676 & salame & 305,801 \\
\hline
\end{tabular}


Como pescado, estão incluídos os peixes de diversas espécies e formas de apresentação e outros produtos da pesca não identificados no momento da fiscalização e assinalados no termo de fiscalização desta forma.

Estão incluídos como laticínio os produtos de laticínio não identificados no momento da fiscalização.

Os resultados da Tabela 2 confirmam os apresentados na Figura 3 de que o produto queijo foi o mais apreendido indicando sua regularidade em todos os anos, fator que não foi observado para nenhum dos demais produtos. Dos produtos relacionados na referida tabela, apenas carne, linguiça, salame e mel de abelha, não aparecem em todos os anos descritos.

No período estudado foram apreendidos $1162,594 \mathrm{~kg}$ do produto carne, estimando-se com base no percentual de 85,66\% dos voos não fiscalizados, que entraram no país 6944,756 kg deste produto no mesmo período.

\section{Discussão}

Os objetivos da Vigilância Agropecuária (Brasil, 2006a) estão em acordo com U. S. Department of Agriculture (2003) para quem se torna de grande importância os controles dos alimentos, a começar pela fiscalização pelo serviço veterinário oficial nas fronteiras internacionais, considerada uma excelente estratégia de defesa contra o ingresso de enfermidades.

Os resultados do presente trabalho concordam com Beutlich et al. (2015) de que os alimentos de origem animal trazidos ilegalmente de países representam um risco para a introdução de doenças podendo levar a surtos de doenças animais com custos económicos e sociais significativos e restrições comerciais subsequentes graves.

Como resultado do presente trabalho foi estimado que $14,34 \%$ dos voos foram submetidos a fiscalização pelo Serviço de Vigilância Agropecuária no Aeroporto Internacional do Rio de Janeiro - Galeão - Antônio Carlos Jobim havendo concordância com Beutlich et al. (2015) de que apenas uma pequena fração dos passageiros que chegam é submetida a controles personalizados.

Estes índices de fiscalização de voos foram ainda inferiores quando comparados aos descritos pelo Department of Agriculture Fisheries and Foresty (2013) que faz referência a Austrália onde 9 entre 10 passageiros que chegam são submetidos a fiscalização.

Considerando-se ainda o percentual de $14,34 \%$ de voos fiscalizados, estimou-se que entraram ilegalmente no Brasil no período estudado, um total de 174.661,817 kg de produtos de origem animal diversos, que em função de suas origens ou de suas matérias primas, podem ser considerados de risco por se enquadrarem na lista da OIE - Organização Mundial de Saúde Animal (Organização Internacional de Saúde, 2013) como passíveis veiculadores de patologias para os animais.

Todas as apreensões obedeceram ao que determina Brasil (2006a) sobre a destruição de produtos agropecuários apreendidos por não terem a devida autorização de importação ou certificação.

\section{Conclusões}

Com base nos resultados obtidos no presente estudo, pode-se concluir que: o ano de 2013 foi considerado o de maior possibilidade de entrada de produtos potencialmente de risco, em função de ter sido o de menor quantitativo de apreensões. Não se observou uma regularidade de apreensões que pudesse caracterizar sazonalidade, entretanto com exceção de 2012, os meses com maiores apreensões corresponderam ao segundo semestre de cada ano. Da mesma forma no estudo comparativo de cada ano isoladamente não foi possível identificar curva ascendente ou descendente ao se cotejar as apreensões mensais, caracterizando não haver parâmetros de comparação entre eles. Todos os voos que chegam ao Aeroporto Internacional do Rio de Janeiro devam ser considerados de perigo zoo-sanitário em função dos produtos apreendidos e suas origens se enquadrarem na lista elaborada pela OIE (Organização Internacional de Saúde, 2013) como potenciais veiculadores de processos patológicos para os animais e pela importância do Brasil na produção e exportação de alimentos de origem animal e, a falta de definição por parte do Serviço de Vigilância Agropecuária para os voos a serem fiscalizados conduz a uma situação considerada crítica, já que o protocolo de atuação fica a critério de cada equipe de fiscalização, não havendo uma regularidade com respeito a esta variável. 
Pelas observações do autor, a esta indefinição agrega-se o principal fator responsável pelo baixo índice de fiscalização que é a falta de autonomia por parte do Serviço de Vigilância Agropecuária para selecionar os voos a serem fiscalizados, pois a interpretação da Constituição da República Federativa do Brasil da precedência da Receita Federal do Brasil sobre os demais órgãos que atuam nas barreiras internacionais limita a escolha dos passageiros a serem fiscalizados, aumentando a possibilidade da entrada de produtos de origem animal potencialmente representativo de risco sanitário, havendo assim, necessidade de elaboração de um plano de atuação de forma a aumentarem as possibilidades de interceptação de produtos irregulares, bem como, a atualização na legislação brasileira de forma a conferir ao Fiscal Federal Agropecuária autonomia para executar a sua ação fiscalizadora dentro dos preceitos profissionais e legais, sem interferência de outros órgãos alheios aos conhecimentos técnicos que a função requer.

\section{Referências}

Beutlich, J., Hammerl, J. A., Appel, B., Nöckler, K., Helmuth, R., Jöst, K., Ludwig, M. L., Hanke, C., Bechtold, D., \& Mayer-Scholl, A. (2015). Characterization of illegal food items and identification of foodborne pathogens brought into the European Union via two major German airports. International Journal of Food Microbiology, 209, 13-19. http://dx.doi.org/10.1016/j.ijfoodmicro.2014.10.017. PMid:25454792.

Brasil, Ministério da Agricultura, Pecuária e Abastecimento (1998, 22 de junho). Portaria SDA n.297, de 22 de junho de 1998. Cria o Programa de Vigilância Agropecuária Internacional no âmbito de atuação da Secretaria de Defesa Agropecuária deste Ministério. Brasília: Diário Oficial da Republica Federativa do Brasil.

Brasil, Presidência da República, Casa Civil, Subchefia de Assuntos Jurídicos. (2006a, 30 de março). Decreto 5741 de 30 de março de 2006. Regulamenta os artigos 27 A, 28 A e 29 A da lei no 8171 de 17 de janeiro de 1991, organiza o Sistema Único de Atenção a Sanidade Agropecuária e dá outras providências. Brasília: Diário Oficial da Republica Federativa do Brasil.

Brasil, Tribunal de Contas da União, Secretaria de Fiscalização e Avaliação de Programas de Governo. (2006b). Relatório de avaliação de programa: ações de vigilância e fiscalização no trânsito internacional de produtos agropecuários. Brasília: Relator Ministro Benjamin Zylmer.

Brasil, Ministério da Agricultura, Pecuária e Abastecimento. (2015a). Animal: mercado interno. Recuperado em 10 de dezembro de 2015, de http://www.agricultura.gov.br/animal/mercado-interno

Brasil, Ministério da Agricultura, Pecuária e Abastecimento. (2015b). Animal: exportação. Recuperado em 10 de dezembro de 2015, de http://www.agricultura.gov.br/animal/exportacao

Brasil, Ministério da Agricultura, Pecuária e Abastecimento. Serviço de Vigilância Agropecuária. (2015c). Aeroporto Internacional do Rio de Janeiro: relatório estatístico de fiscalização de cargas e bagagens - anos 2010, 2011, 2012, 2013 e 2104. Brasília: SVA/AIRJ.

Corbellini, L. G. (2007). O uso da epidemiologia no diagnóstico populacional e implicações no comércio internacional: determinação de zona livre de doença(s). Acta Scientiae Veterinariae, 35(supl. 1), 1-8.

Department of Agriculture Fisheries and Foresty-DAFF. (2013). Travel information. Recuperado em 10 de janeiro de 2016, de www.daff.gov.au/biosecurity/travel

Horst, H. S., Dijkhuizen, A. L. A., Huirne, R. B. M., \& De Leeuw, P. W. (1998). Introduction of contagious animal disease into The Netherlands: elicitation of expert opinions. Livestock Production Science, 53(3), 253-264. http://dx.doi.org/10.1016/S0301-6226(97)00098-5.

Moura, J. A. (2004, 20-24 de setembro). Análise de risco como ferramenta na prevenção e controle de doenças. In Semana de Caprinocultura e Ovinocultura Brasileira: Vol. 4. Sobral: Embrapa Caprinos. Recuperado em 10 de Maio de 2015, de http://ainfo.cnptia.embrapa.br/digital/cbitstream/item/60590/1/AAC-Analise-de-risco.pdf

Organização Internacional de Saúde - OIE. (2013). Enfermedades, infecciones e infestaciones de la lista da OIE en vigor en 2013. Recuperado em 10 de setembro de2013, de http://www.oie.int/es/sanidad-animal-en-el-mundo/ enfermedades-de-la-lista-de-la-oie-2013

Organização Internacional de Saúde - OIE. (2016). Enfermedades, infecciones e infestaciones de la lista da OIE en vigor en 2016. Recuperado em 10 de setembro de 2016, de http //www.oie.int/es/sanidad-animal-en-el-mundo/ oie-listed-diseases-2016

Rich, K. M., Winter-Nelson, A., \& Brozovic, N. (2007). An integrated epidemiological-economic analysis of foot and mouth disease: applications to the southern cone of South America. American Journal of Agricultural Economics, 89(3), 682-697. http://dx.doi.org/10.1111/j.1467-8276.2007.01006.x.

Soncini, R. A. (2004, 05-07 de abril). Barreiras sanitárias na avicultura. In Simpósio Brasil Sul de Avicultura SIM: Vol. 5. Chapecó: Embrapa. Recuperado em 10 de Maio 2015, de http://www.cnpsa. embrapa.br/sgc/ sgc_publicacoes/anais_V_bsa_Soncini.pdf

Tavares, L. P., \& Ribeiro, K. C. S. R. (2007). Desenvolvimento da avicultura de corte brasileira e perspectiva frente a influenza aviária. Organizações Rurais \& Agroindustriais, 9(1), 79-88. 
Tokarnia, C. H., Peixoto, P. V., Döbereiner, J., Barros, S. S., \& Riet-Correa, F. (2004). Surto de peste suína africana ocorrido em 1978 no município de Paracambi, Rio de Janeiro. Pesquisa Veterinária Brasileira, 24(4), 223-238. http://dx.doi.org/10.1590/S0100-736X2004000400010.

U. S. Department of Agriculture - USDA. (2003). Application for recognition of the animal health status of a region - code of federal regulations - title 9 - part 92.2. Washington: USDA.

Weiblen, R. (2013). Barreiras sanitárias na comercialização de suínos e produtos derivados: a visão acadêmica. Santa Maria: Universidade Federal de Santa Maria, Departamento de Medicina Veterinária Preventiva, Microbiologia e Parasitologia. Recuperado em 10 de setembro de 2013, de http://www.cnpsa.embrapa.br/ abraves-sc/pdf/ Palestras 2001/RudiWeiblen.pdf 